\title{
Evaluation of exposure to polycyclic aromatic hydrocarbons in a coke production and a graphite electrode manufacturing plant: assessment of urinary excretion of 1-hydroxypyrene as a biological indicator of exposure
}

\author{
J P Buchet, J P Gennart, F Mercado-Calderon, J P Delavignette, L Cupers, R Lauwerys
}

\begin{abstract}
Objectives-Characterisation of the airborne concentration of 13 polycyclic aromatic hydrocarbons (PAHs) at various workplaces in a graphite electrode and a coke production plant. Validation of the urinary excretion of 1-hydroxypyrene (hydroxypyrene) as a biological marker of exposure to PAH.

Design-Cross sectional study of workers exposed to PAHs (106 in the graphite electrode producing plant and 16 in the coke works).

Methods-Personal air sampling during at least six hours per workshift using a glass fibre filter and a Chromosorb 102 solid sorbent tube and analysis of PAHs by high performance liquid chromatography (HPLC) and spectrofluorometric detection (SFD). Collection of spot urine samples before and after the shift and analysis of 1-hydroxypyrene by HPLC and SFD.

Results-The workers most exposed to PAHs were those occupied at the topside area of the coke oven plant and those working in the blending and impregnation areas of the graphite electrode producing plant (mean airborne concentration of total PAHs: 199 and $223 \mu \mathrm{g} / \mathrm{m}^{3}$ respectively). Except for naphthalene and perylene, the relative proportion of the different PAHs did not differ between the plants. Pyrene concentration in air was highly correlated with the total airborne PAH concentration $(r=0.83, p<0.0001)$ and the correlation coefficients between hydroxypyrene concentration in postshift urine
\end{abstract}

Industrial Toxicology and Occupational Medicine Unit, Catholic University of Louvain, Clos Chapelleaux-Champs PO Box 30.54, B-1200 Brussels, Belgium

J P Buchet, J P Gennart, F Mercado-Calderon, J P Delavignette, L Cupers, R Lauwerys samples and pyrene or total PAHs in air were $0.67(p<0.0001)$ and $0.72(p<0.0001)$ respectively. Excretion of hydroxypyrene doubled when the exposure to pyrene in air increased 10-fold. The half life for the urinary excretion of hydroxypyrene was around 18 hours $(95 \%$ confidence interval 16-1-19.8). Smoking habits only explained $2 \cdot 3 \%$ of the variance in hydroxypyrene excretion compared with $45 \%$ for the pyrene concentration in air.

Conclusion-The determination of the urinary excretion of hydroxypyrene in postshift urine samples can be used as a suitable biomarker to assess individual exposure to PAHs in coke ovens and in graphite electrode manufacturing plants.

(British Journal of Industrial Medicine 1992;49:761-768)

Polynuclear aromatic hydrocarbons (PAHs) are generated when natural or synthetic organic materials are burnt in the presence of a suboptimal oxygen supply. Quantities of up to $20 \mu \mathrm{g} / \mathrm{kg}$ occur in some foods (for example, smoked products). They are present in ambient air mainly due to their release from motor vehicles, domestic coal or oil fired heating systems, and various industrial sources. They are also found in high concentration in some workplaces (for example, coke ovens, aluminium reduction plants, the steel industry, the asphalt industry, creosote impregnating plants, and gas and petroleum industries). About 500 PAHs have been detected in the air but in practice only a few are routinely measured. They are lipid soluble compounds and can be absorbed into the body by all the normal routes. Several PAHs (for example, dibenz(a,h)anthracene, benzo $(\alpha)$ pyrene) are capable of producing tumours in numerous test species and PAHs can induce skin and lung cancer in humans. ${ }^{1}$

Jongeneelen et $a l^{2}$ have reported an increased urinary excretion of 1-hydroxypyrene (hydroxy- 
pyrene), the hydroxylated metabolite of pyrene, in the urine of subjects exposed to mixtures of PAHs. As the proportion of pyrene in airborne mixtures of PAHs from different sources does not vary greatly, it has been suggested that the concentration of hydroxypyrene in urine might be used as a biological indicator of overall exposure to PAHs. This study reports on the relation between the urinary excretion of hydroxypyrene and the intensity of exposure to airborne PAHs in workers from a coke oven and a graphite electrode producing plant.

\section{Materials and methods}

\section{STUDY POPULATION}

The study was carried out in two plants, one producing coke and the other graphite electrodes for the steel industry, and involved 122 workers. Workers from the coke producing plant were divided into two groups: group $\mathrm{Cl}(\mathrm{n}=10)$ included workers on the bench side and group C2 $(n=6)$ those on the top side of the coke ovens ( $\operatorname{see}^{3}$ for a detailed description of the production process). The main steps in graphite electrode production are (1) grinding and mixing of raw materials (coke and hot coal tar pitch), (2) pressure moulding of the crude paste, (3) baking, (4) impregnation with liquid tar, (5) graphitisation, and (6) finishing. Workers from the graphite electrode plant were divided into six groups: group $\mathrm{Gl}(\mathrm{n}=10)$, workers engaged in the end product conditioning (polishing, thread grooving, rodding); group G2 $(n=25)$, workers in charge of the second (and last) thermal treatment of the electrodes at $2800^{\circ} \mathrm{C}$; group $\mathrm{G} 3(\mathrm{n}=6)$, workers in charge of the Stein oven for the progressive $\left(1^{\circ} \mathrm{C} /\right.$ hour) heating of the raw electrodes up to $800^{\circ} \mathrm{C}$; group G4 $(n=17)$, maintenance and repair staff (mainly electricians and mechanics); group G5 $(n=14)$, workers engaged in the grinding and mixing at moderate temperature $\left(150^{\circ} \mathrm{C}\right)$ of the raw components (coke and coal tar pitch) and performing the extrusion of electrodes; group G6 $(n=8)$, workers in charge of the electrode impregnation (dipping in liquid tar at $280^{\circ} \mathrm{C}$ to fill the pores resulting from the first thermal treatment). Warehousemen, clerks, drivers, and shop stewards of both plants were combined as one group (group LEX, $\mathrm{n}=11)$. A group of office workers from the graphite electrode producing plant was selected as controls (group REF, $\mathbf{n}=15$ ).

Each worker provided a urine sample before and after the workshift during which the airborne concentration of PAHs was monitored with a personal sampling system. Also, 15 workers from groups G5 and $\mathrm{G} 6$ of the graphite electrode manufacturing plant collected spot urine samples at $8.00 \mathrm{am}, 4.00 \mathrm{pm}$, and $10.00 \mathrm{pm}$ during three or four days off work after a five day work period.

\section{AIR SAMPLING}

Light PAHs with two or three aromatic rings are mainly present in the vapour phase and can be retained on an adsorbent such as Chromosorb 102 whereas heavier compounds are mainly retained on a filter as particulates. ${ }^{4}$

Each worker was thus equipped with a personal air sampler. Air was aspirated at a flow rate of $2 \mathrm{l} / \mathrm{min}$ by a battery powered air sampling pump (model 224 PCEXR3, SKC Inc, Eighty Four, $\mathrm{Pa}$, USA). Particles were retained on a glass microfibre filter (GFF, Whatman, diameter $3.7 \mathrm{~cm}$ ) and vapours were adsorbed on Chromosorb 102 contained in a tube (SKC Inc) placed between the filter and the pump. Tubes and filters were kept in a refrigerated dark room until analysis (within two weeks). The air sampling lasted up to six hours but in cases of heavy pollution, several one or two hour successive samples were collected.

\section{DETERMINATION OF PAH CONCENTRATIONS}

The adsorbent sections and the filter were extracted with methanol, chosen because it is readily miscible with the chromatographic mobile phase and does not interfere with the detection of PAHs. ${ }^{5}$ Thirteen PAHs (naphthalene, fluorene, phenanthrene, anthracene, fluoranthene, pyrene, benz $(\alpha)$ anthracene, chrysene, benzo(e)pyrene, perylene, benzo $(\alpha)$ pyrene, $\operatorname{dibenz}(\mathrm{a}, \mathrm{h})$ anthracene, and benzo $(\mathrm{g}, \mathrm{h}, \mathrm{i})$ perylene $)$ were measured by high performance liquid chromatography and fluorescence detection. A ChromSpher PAH column (200 mm length, $3 \mathrm{~mm}$ internal diameter) from Chrompack was used. Elution was performed at a flow rate of $0.5 \mathrm{ml} / \mathrm{min}$ with a gradient of water/acetonitrile delivered by two high pressure pumps (models 302 and 305, Gilson Medical Electronics (Villiers le Bel, France)). At the start, the eluent was a 50/50 mixture, it had changed to pure acetonitrile by 15 minutes; pure acetonitrile was delivered for 12 further minutes and its concentration was then reduced to the 50/50 mixture in two minutes; a re-equilibration of the column was allowed for six minutes before the next analysis. Samples were injected with an autosampler (Marathon; Spark, Holland).

The detection of PAHs was performed by fluorimetry (821-FP Jasco spectrofluorometer, Gynkotek apparatus, Germering bei München, Germany); for naphthalene, fluorene, and phenanthrene the excitation and emission wavelengths were 280 and $350 \mathrm{~nm}$; for the other compounds, 305 and $430 \mathrm{~nm} .{ }^{6}$ Standard PAH mixtures (Alltech Associates, Deerfield IL, USA) were used as reference materials. Results are reported either as the individual sum of each PAH retained on the adsorbent and the filter or as the sum of all PAHs measured (total PAH concentration). Tube breakthrough was considered to have occurred when the second sorbent section of the Chromosorb 
Table 1 Determination of $P A H$ concentration in air: recovery and detection limit

\begin{tabular}{|c|c|c|c|}
\hline \multirow[b]{2}{*}{ Compound } & \multicolumn{2}{|c|}{ Recovery (\%) from } & \multirow[b]{2}{*}{ Detection limit $\left(\mathrm{ng} / \mathrm{m}^{3}\right.$ ) } \\
\hline & Glass fibre filter & Chromosorb 102 & \\
\hline $\begin{array}{l}\text { Naphthalene } \\
\text { Fluorene } \\
\text { Phenanthrene } \\
\text { Anthracene } \\
\text { Fluoranthene } \\
\text { Pyrene } \\
\text { Benz( } \alpha \text { )anthracene } \\
\text { Chrysene } \\
\text { Benzo(e)pyrene } \\
\text { Perylene } \\
\text { Benzo(a)pyrene } \\
\text { Dibenzo(a,h)anthracene } \\
\text { Benzo(g,h,i)perylene }\end{array}$ & $\begin{array}{l}101(3) \star \\
102(4) \\
102(4) \\
102(5) \\
103(5) \\
104(6) \\
101(4) \\
104(9) \\
100(7) \\
98(5) \\
102(5) \\
102(5) \\
102(4)\end{array}$ & $\begin{array}{l}94(3) \\
71(3) \\
66(4) \\
63(1) \\
57(2) \\
58(6) \\
47(6) \\
46(3) \\
33(5) \\
27(3) \\
34(9) \\
31(3) \\
39(5)\end{array}$ & $\begin{array}{r}3 \\
2 \\
10 \\
8 \\
5 \\
12 \\
5 \\
12 \\
7 \\
5 \\
2 \\
7 \\
8\end{array}$ \\
\hline
\end{tabular}

*Mean (SD) of six experiments.

tube contained more than $10 \%$ of the amount collected in the first section; in this case, the data were discarded.

\section{DETERMINATION OF HYDROXYPYRENE EXCRETION}

The measurement of urinary hydroxypyrene excretion was carried out by the technique of Jongeneelen et $a l .^{7}$ This technique included a prior enzymatic hydrolysis of the conjugates with a mixture of glucuronidase and sulphatase; the next step was a sample purification on octadecyl silica cartridges (Bond-Elut $100 \mathrm{mg}$, Analytichem, Harbor City, CA, USA) performed with an Aspec System from Gilson. Chromatography was carried out with an ET 250/8/4 Nucleosil 10C18 column (Macherey-Nagel, Düren, Germany); two Gilson pumps (models 302 and 305) delivered either pure acetonitrile (solvent A) or $10 \%$ acetonitrile in water containing $0.5 \mathrm{ml}$ glacial acetic acid/1 (solvent B) at a flow rate of $1 \mathrm{ml} / \mathrm{min}$ to make the elution gradient: from 100 to $20 \%$ solvent B in 25 minutes, from 20 to $0 \%$ solvent $B$ in two minutes, isocratic (pure solvent A) elution during three minutes, back to $100 \%$ solvent $B$ in two minutes and re-equilibration of the column during eight minutes before the next analysis. Hydroxypyrene was detected by fluorimetry (excitation: $240 \mathrm{~nm}$; emission: $390 \mathrm{~nm}$; 821-FP Jasco spectrofluorometer). The calibration was made with a control urine sample spiked with $10 \mu \mathrm{g}$ hydroxypyrene/1 (Janssen, Beerse, Belgium); the detection limit was $0.2 \mu \mathrm{g} / 1$. Results were standardised to $1 \mathrm{~g}$ urinary creatinine.

OTHER BIOLOGICAL MEASUREMENTS

Urinary creatinine was determined by the colorimetric method of Jaffé using a Technicon RA1000 automate (Tarrytown, NY, USA). The urinary thiocyanate concentration was measured by the technique of Pettigrew and Fell ${ }^{8}$ and expressed as $\mathrm{mg} / \mathrm{g}$ creatinine.
STATISTICAL ANALYSIS

For statistical analysis, the SAS/STAT software ${ }^{9}$ was used. The distributions of PAH concentrations in air and hydroxypyrene in urine was normalised by a logarithmic transformation. Values below the detection limit were given a value equal to half of the detection limit as suggested by Hornung and Reed. ${ }^{10}$

\section{Results}

EVALUATION OF THE ANALYTICAL TECHNIQUE FOR MEASUREMENT OF PAHS IN AIR

Table 1 presents the percentage recovery of each compound when an aliquot of a standard PAH mixture was directly deposited on a glass fibre filter or in a tube containing Chromosorb 102. The detection limit for each compound was calculated on the basis of a signal equal to three times the background and an air sample volume equal to $0.5 \mathrm{~m}^{3}$.

The recovery of PAHs with four and more aromatic rings from Chromosorb 102 is quite low but because in practice these compounds are almost completely retained on the glass fibre filter, the recovery of the technique was considered satisfactory. Even the volatile PAHs were significantly retained on the filter, probably due to their adsorption on particulate materials. For example, in both the coke and the graphite electrode producing plants, the amounts of naphthalene, fluorene, and phenanthrene found on the filter represented on average 34,84 , and $77 \%$ of the total amounts collected.

\section{AIRBORNE CONCENTRATIONS OF PAHS}

The workers were subdivided into various groups according to their main workplaces or activities (see materials and methods). Table 2 presents the mean total airborne PAH concentrations. The workers most exposed to PAHs were those occupied at the topside area of the coke oven plant (group C2) and 
Table 2 Mean total PAH concentrations in various work areas from a coke production and a graphite electrode manufacturing plant

\begin{tabular}{|c|c|c|c|c|}
\hline \multirow[b]{2}{*}{ Groups } & \multirow[b]{2}{*}{ No } & \multicolumn{3}{|c|}{ Total $P A H$ concentration $\left(\mu \mathrm{g} / \mathrm{m}^{3}\right)$} \\
\hline & & Geometric mean & Median (geometric SD) & Range \\
\hline $\begin{array}{l}\text { REF } \\
\text { LEX } \\
\text { C1 } \\
\text { C2 } \\
\text { G1 } \\
\text { G2 } \\
\text { G3 } \\
\text { G4 } \\
\text { G5 } \\
\text { G6 }\end{array}$ & $\begin{array}{r}15 \\
11 \\
10 \\
6 \\
10 \\
25 \\
6 \\
17 \\
14 \\
8\end{array}$ & $\begin{array}{r}0.3 \\
3 \cdot 0 \\
14 \cdot 2 \\
198 \cdot 7 \\
2 \cdot 8 \\
4 \cdot 1 \\
17 \cdot 4 \\
12.5 \\
96.0 \\
222.6\end{array}$ & $\begin{array}{r}0.2(2.9) \\
3.7(4.0) \\
25.1(4.3) \\
241.2(4 \cdot 1) \\
2.7(2 \cdot 1) \\
4.3(3.8) \\
33.2(5.9) \\
11.1(4.0) \\
87.0(2.9) \\
255.1(3.4)\end{array}$ & $\begin{array}{c}0 \cdot 1-6 \cdot 8 \\
0 \cdot 1-32 \cdot 4 \\
0 \cdot 7-74 \cdot 2 \\
26 \cdot 6-959 \\
1 \cdot 0-9 \cdot 3 \\
0 \cdot 2-50 \cdot 9 \\
100-117 \\
0 \cdot 6-251 \\
17 \cdot 7-551 \\
20 \cdot 8-1212\end{array}$ \\
\hline
\end{tabular}

those working in the blending and the impregnation areas of the graphite electrode producing plant (group G6).

To compare the proportion of the different airborne PAHs present in both plants, the concentration of each PAH found in each air sample was expressed in per cent of the total PAH concentration found in the same sample. The arithmetic mean and standard deviation (SD) were calculated for each plant separately; Figure 1 summarises the results. The PAH profile was only slightly different between the two plants. A similar distribution was found for 11 compounds; only the naphthalene and perylene

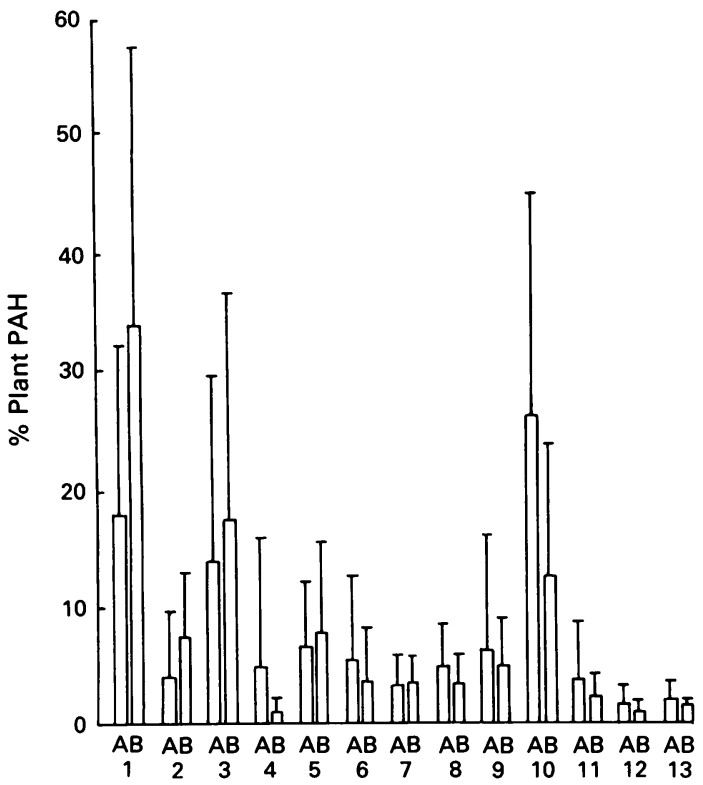

Figure 1 Relative abundance of 13 PAHs in the air of $(A)$ a graphite electrode manufacturing and $(B)$ a coke production plant (arithmetic mean $+S D$ ). 1 naphthalene; 2 fluorene; 3 phenanthrene; 4 anthracene; 5 fuoranthene; 6 pyrene; 7 benz $(\alpha)$ anthracene; 8 chrysene;

9 benzo(e)pyrene; 10 perylene; 11 benzo $(\alpha)$ pyrene;

12 dibenz $(a, h)$ anthracene; 13 benzo $(g, h, i)$ perylene. proportions differed between plants. Similar calculations for pyrene showed that on average this compound represented 2 to $8.5 \%$ of the total PAHs measured at the several workplaces (fig $2 \mathrm{~A}$ ) whereas the mean contribution of the sum of three carcinogenic compounds (benzanthracene, benzo $(\alpha)$ pyrene, and dibenz $(\mathrm{a}, \mathrm{h})$ anthracene) ranged between 5 and $12 \%$ of the total PAH (fig 2B). Excellent correlations were found between pyrene in air and total PAHs $(\mathrm{n}=122 ; \mathrm{r}=0.90, \mathrm{p}<0.001)$ and between pyrene and the sum of the three carcinogenic PAHs $(\mathrm{n}=122 ; \mathrm{r}=0.83, \mathrm{p}<0.001)$.

\section{EXCRETION OF HYDROXYPYRENE}

Kinetics of elimination of hydroxypyrene in urine

Fifteen workers from the coke production and the graphite electrode manufacturing plants provided spot urine samples at the end of a work week and at various times during the following rest period extending up to four days. The hydroxypyrene concentration was expressed in per cent of the concentration in the end of shift sample. Table 3 presents the concentration of hydroxypyrene in the end of shift sample for each worker and the correlation coefficient (with associated $p$ value) of the relation between the percentage (log scale) of the urinary hydroxypyrene concentration and the time interval since the end of work. Assuming a first order elimination model, the half life has been calculated from the slope of the regression line and is given in the last column. On average, after stopping exposure, the time needed for a $50 \%$ reduction of the hydroxypyrene concentration in urine amounts to 18 hours with a $95 \%$ confidence interval $(95 \% \mathrm{CI})$ ranging from $16 \cdot 1$ to $19 \cdot 8$ hours.

\section{Relation between the urinary excretion of} hydroxypyrene and exposure to airborne PAHS

For each worker a spot urine sample was collected before and after the workshift during which the concentration of PAHs in the breathing zone was measured. On an individual basis, the coefficient of correlation of the relation between concentration of hydroxypyrene in postshift urine samples and pyrene 

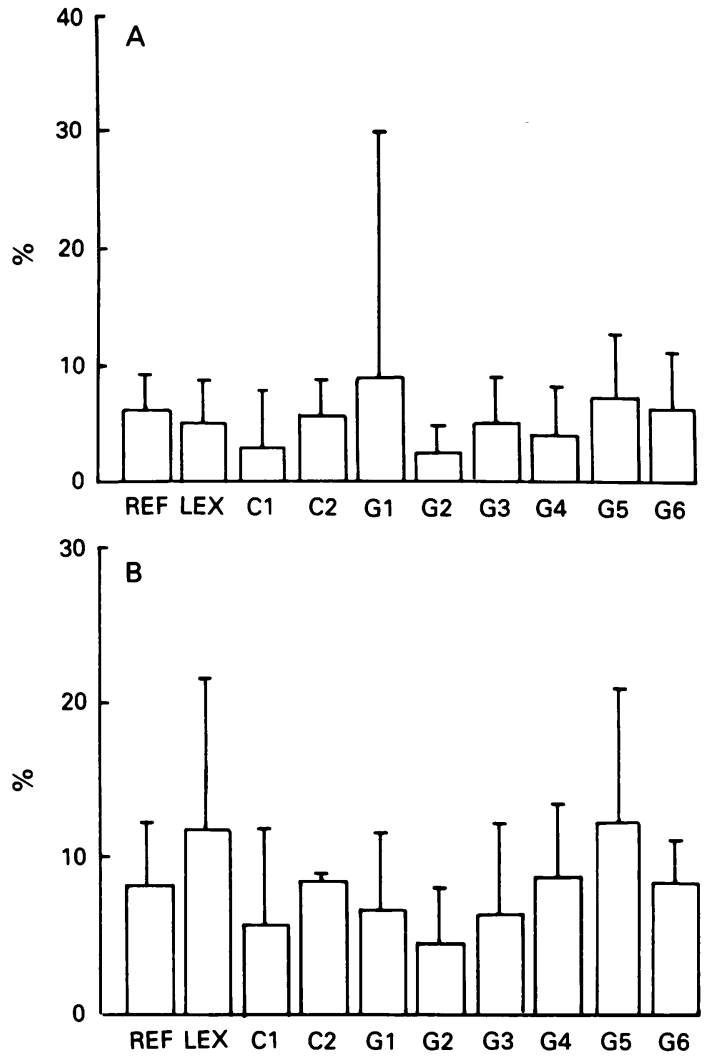

Figure 2 Relative abundance of $(A)$ pyrene and $(B)$ the sum of benz $(\alpha)$ anthracene, benzo $(\alpha)$ pyrene, and dibenz $(a, h)$ anthracene in the air of different work areas from a coke production and a graphite electrode manufacturing plant (arithmetic mean $+S D$ ).

in air amounted to $0.67(\mathrm{n}=122, \mathrm{p}<0.0001)$; it was not significantly greater $(r=0.69, n=102$, $\mathrm{p}<0.001$ ) when only the increase in hydroxypyrene concentration over the shift was taken into consideration and corrected for the residual elimination of hydroxypyrene resulting from previous exposures to PAH. The excretion of hydroxypyrene (end of shift concentration) was also significantly correlated with total concentration of PAHs in air samples $(n=122$; $\mathrm{r}=0.72, \log$ hydroxypyrene $(\mu \mathrm{g} / \mathrm{g}$ creatinine) $=-0.1132+0.4055 \log$ total PAHs $\left.\left(\mu \mathrm{g} / \mathrm{m}^{3}\right)\right)$. For each group of workers the geometric means of the pre and postshift urinary hydroxypyrene concentrations were calculated for smokers and non-smokers separately. Table 4 presents the data together with the corresponding mean pyrene concentrations in air during the workshift. On a group basis the relation (log scales) between exposure to pyrene and the excretion of its hydroxylated metabolite in urine was high but was not significantly different whether the excretion was expressed as the hydroxypyrene concentration in urine at the end of the workshift ( $\mathrm{n}=20 ; \mathrm{r}=0.74, \mathrm{p}<0.0001$ ) or as the change in concentration over the shift $(n=20 ; r=0 \cdot 76$, $\mathrm{p}<0.0001$ ).

The change in concentration of hydroxypyrene over the shift was statistically analysed by a two way analysis of variance involving job category, smoking habits, and a test for interaction. A statistically significant influence $(p<0.0001)$ of job category was found but no significant effect of smoking and interaction terms between both factors. A multivariate regression analysis (log scales) evaluating the increase over the shift of the urinary hydroxypyrene concentration as a function of pyrene in air, smoking habits (coded 0 or 1), and an interaction term between both was also performed on the individual workers or on the group data (table 5). Again the only variable significantly influencing hydroxypyrene excretion was concentration of pyrene in air.

Another attempt to assess the importance of smoking as a potentially confounding factor for excretion of hydroxypyrene was made using the concentration of thiocyanate in urine. ${ }^{11}$ Possible interference of occupational exposure to hydrogen cyanide was negligible because at most it involved 16 workers from the coke oven plant where low concentration of hydrogen cyanide were sometimes detected. ${ }^{12}$ The results of a multivariate regression analysis linking the postshift hydroxypyrene excretion with the concentration of pyrene in air during the shift and

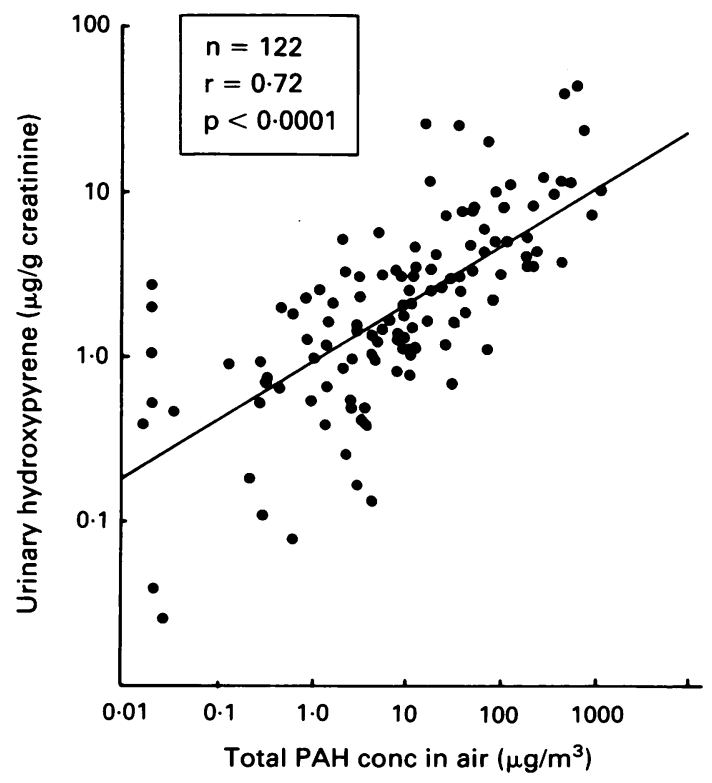

Figure 3 Relation between hydroxypyrene concentration in postshift urine and total concentration of PAHs in air. 
Table 3 Elimination kinetics of hydroxypyrene in 15 workers exposed to PAHs

\begin{tabular}{|c|c|c|c|c|c|}
\hline Worker & $\begin{array}{l}\text { Hydroxypyrene in end } \\
\text { of last shift urine } \\
\text { sample ( } \mu g / g \text { creatinine) }\end{array}$ & $\begin{array}{l}\text { No of urine samples } \\
\text { collected during four } \\
\text { days at rest }\end{array}$ & $r^{\star}$ & p value & $\begin{array}{l}\text { Time for } 50 \% \\
\text { reduction in urine } \\
\text { concentration ( } h \text { ) }\end{array}$ \\
\hline $\begin{array}{r}1 \\
2 \\
3 \\
4 \\
5 \\
6 \\
7 \\
8 \\
9 \\
10 \\
11 \\
12 \\
13 \\
14 \\
15\end{array}$ & $\begin{array}{r}17.0 \\
12.0 \\
3.9 \\
7.4 \\
12.5 \\
19.3 \\
44.7 \\
26.0 \\
14.9 \\
6.6 \\
20.3 \\
11.4 \\
13.5 \\
19.9 \\
8.2\end{array}$ & $\begin{array}{l}6 \\
6 \\
7 \\
6 \\
6 \\
6 \\
7 \\
7 \\
7 \\
7 \\
5 \\
7 \\
7 \\
7 \\
7\end{array}$ & $\begin{array}{l}0.96 \\
0.96 \\
0.83 \\
0.97 \\
0.94 \\
0.96 \\
0.98 \\
0.92 \\
0.89 \\
0.95 \\
0.94 \\
0.99 \\
0.97 \\
0.90 \\
0.97\end{array}$ & $\begin{array}{l}0.0028 \\
0.0023 \\
0.0209 \\
0.0010 \\
0.0195 \\
0.0020 \\
0.0001 \\
0.0036 \\
0.0068 \\
0.0009 \\
0.0161 \\
0.0001 \\
0.0020 \\
0.0133 \\
0.0020\end{array}$ & $\begin{array}{l}17.0 \\
18.3 \\
13.4 \\
17.5 \\
14.8 \\
15.8 \\
15.9 \\
14.1 \\
26.3 \\
19.3 \\
15.8 \\
16.8 \\
18.9 \\
24.4 \\
21.7\end{array}$ \\
\hline
\end{tabular}

*Correlation coefficient of the relation between the urinary hydroxypyrene concentration (expressed in $\%$ of the end of shift concentration; log scale) and the time interval since the end of work.

the urinary excretion of thiocyanate introduced as independent variables showed that a linear model fitted the findings $\left(\log\right.$ values; $\left.\mathrm{r}^{2}=0.47, \mathrm{p}<0.0001\right)$; however, thiocyanate excretion only explained $2 \cdot 3 \%$ of the variance in excretion of hydroxypyrene.

\section{Discussion}

High PAH concentrations were found in the air of the coke oven plant; at the topside, median and geometric mean values were 241 and $199 \mu \mathrm{g}$ total PAHs $/ \mathrm{m}^{2}$ respectively and they were one order of magnitude lower on the benchside (25 (median) and 14 (geometric mean) $\mu \mathrm{g} / \mathrm{m}^{3}$ ). At both locations, however, the airborne concentrations of PAHs showed a great variation between workers (the geometric standard deviation of the measurements exceeded 4). Naphthalene, phenanthrene, perylene, fluoranthene, and fluorene were the most abundant PAHs in the air of the coke oven plant: they represented $34,18,13,7 \cdot 5$, and $7 \%$ of the total amount respectively. Benzo( $\alpha)$ pyrene, the carcinogenic PAH representative, occurred at a concentration equal to $2 \%$ of the total amount of PAHs-that is, between 0.002 and $2 \mu \mathrm{g} / \mathrm{m}^{3}$ (geometric mean 0.04 ) on the benchside and between 0.8 and $31.8 \mu \mathrm{g} / \mathrm{m}^{3}$ (geometric mean 5.85) on the topside of the coke factory. Pyrene represented about $3 \%$ of the total amount of PAHs in the air of the coke oven plant; its concentration ranged between 0.01 and 2.86 (geometric mean 0.07 ) and between 1.53 and $88.3 \mu \mathrm{g} / \mathrm{m}^{3}$ (geometric mean 9.44) in the bench and topside areas respectively.

Table 4 Hydroxypyrene concentration in pre and postshift urine samples

\begin{tabular}{|c|c|c|c|c|c|}
\hline \multirow[b]{2}{*}{ Group } & \multirow[b]{2}{*}{ Smoking habits } & \multicolumn{3}{|c|}{ Hydroxypyrene concentration $(\mu g / g \text { creatinine })^{\star}$} & \multirow{2}{*}{$\begin{array}{l}\text { Pyrene in } \\
\text { air }\left(\mu g / m^{3}\right)^{\star}\end{array}$} \\
\hline & & No & Preshift sample & Postshift sample & \\
\hline \multirow[t]{2}{*}{ REF } & NS & 9 & $0 \cdot 15$ & 0.33 & 0.01 \\
\hline & S & 6 & 0.32 & 0.36 & 0.02 \\
\hline \multirow[t]{2}{*}{ LEW } & NS & 5 & $0 \cdot 28$ & 0.35 & 0.03 \\
\hline & $S$ & 6 & 0.94 & 0.99 & $0 \cdot 16$ \\
\hline \multirow[t]{2}{*}{$\mathrm{Cl}$} & NS & 4 & $2 \cdot 27$ & $2 \cdot 36$ & 0.05 \\
\hline & $\mathrm{S}$ & 6 & 0.46 & $1 \cdot 45$ & 0.09 \\
\hline C2 & $\begin{array}{l}\text { NS } \\
S\end{array}$ & $\begin{array}{l}3 \\
3\end{array}$ & $\begin{array}{l}4 \cdot 67 \\
3 \cdot 22\end{array}$ & $\begin{array}{l}10 \cdot 91 \\
11 \cdot 72\end{array}$ & $\begin{array}{r}15 \cdot 87 \\
5 \cdot 62\end{array}$ \\
\hline \multirow{2}{*}{ G1 } & NS & 3 & 0.85 & 1.07 & 0.10 \\
\hline & $\mathrm{S}$ & 7 & 0.88 & 1.06 & 0.04 \\
\hline \multirow[t]{2}{*}{ G2 } & NS & 8 & 0.55 & $1 \cdot 10$ & 0.05 \\
\hline & S & 17 & $1 \cdot 21$ & 1.52 & 0.05 \\
\hline \multirow[t]{2}{*}{ G3 } & NS & 2 & $5 \cdot 28$ & 4.94 & $0 \cdot 20$ \\
\hline & S & 4 & $3 \cdot 15$ & 6.04 & 0.39 \\
\hline \multirow[t]{2}{*}{ G4 } & NS & 15 & 1.60 & $2 \cdot 33$ & $0 \cdot 21$ \\
\hline & $S$ & 2 & $2 \cdot 67$ & $7 \cdot 26$ & 0.13 \\
\hline \multirow[t]{2}{*}{ G5 } & NS & 5 & $3 \cdot 23$ & $5 \cdot 75$ & $10 \cdot 75$ \\
\hline & $S$ & 9 & $4 \cdot 34$ & $5 \cdot 47$ & 3.52 \\
\hline \multirow[t]{2}{*}{ G6 } & NS & 3 & $6 \cdot 13$ & 7.99 & $27 \cdot 27$ \\
\hline & $\mathbf{S}$ & 5 & $6 \cdot 21$ & $9 \cdot 58$ & $3 \cdot 35$ \\
\hline
\end{tabular}

$\star$ Geometric mean.

$\mathrm{N}=$ non smoker; $\mathrm{S}=$ smoker. 
Table 5 Multiple regression analysis of the increase in concentration of hydroxypyrene in urine over the shift as a function of concentration of pyrene in air, smoking habits, and interaction between both factors

\begin{tabular}{lcccc}
\hline & Regression coefficient & $S E$ & ${\text { Partial } r^{2}}$ & $p$ value \\
\hline Model based on individual worker: & & & \\
$\quad$ Intercept & 0.00963 & 0.0958 & 0.9202 \\
Pyrene in air & 0.31904 & 0.0641 & 0.35326 & 0.0001 \\
Smoking habits & 0.02308 & 0.1325 & 0.00034 & 0.8621 \\
Interaction & -0.00218 & 0.0979 & 0.0000 .0 & 0.9823 \\
Model based on group means: & 0.094175 & 0.11003 & 0.75243 & 0.4055 \\
Intercept & 0.482439 & 0.08763 & 0.001 \\
Pyrene in air & 0.130552 & 0.167440 & 0.01004 & 0.4477 \\
Smoking habits & 0.023620 & 0.148937 & 0.00039 & 0.8761 \\
Interaction & & & & \\
\hline
\end{tabular}

The PAH concentrations found in this study are in agreement with previous observations reviewed by the International Agency for Research on $\mathrm{Cancer}^{3}$ especially with regard to benzo $(x)$ pyrene concentration. More recently, however, Jongeneelen et $\mathrm{al}^{13}$ have reported lower PAH concentrations at two coke ovens of a steel plant; pyrene and benzo $(x)$ pyrene mean concentrations were around 2 and $1 \mu \mathrm{g} / \mathrm{m}^{3}$ and the most abundant PAHs were fluoranthene and benzo $(x)$ anthracene. Naphthalene was not measured.

In the graphite electrode producing plant, the air contamination by PAHs in the blending zone (group G5) and in the impregnation zone (group G6) was distinctly higher than in the other work zones; at these two locations the exposure conditions were similar to those found at the topside of coke ovens whereas in the other workplaces (groups G1 to G4) concentrations of PAs were closer to those found at the benchside of the coke factory (table 2). The most abundant PAHs were the same in the air of the graphite electrode producing plant as in that of the coke ovens. $\operatorname{Benzo}(x)$ pyrene and pyrene represented 3.5 and $6 \%$ of the total PAH amount respectively. The geometric means (and ranges) of benzo $(x)$ pyrene concentrations at the workplaces corresponding to groups G1 to G6 were $0.03(0.002-0.4), 0.03(0.002-$ $0.5), 0.04(0.002-1.88), 0.21(0.002-7.53), 5.40(0.57-$ $25 \cdot 1)$, and $6.22(0.83-72.9) \mu \mathrm{g} / \mathrm{m}^{3}$ respectively. In eight similar plants, Lafontaine et al ${ }^{14}$ found that the benzo $(x)$ pyrene concentration was the highest (up to $130 \mu \mathrm{g} / \mathrm{m}^{3}$ ) in the workplaces where raw materials were prepared and electrodes extruded and dipped in liquid $\operatorname{tar}$ (corresponding to groups G5 and G6 in our study) and the lowest (up to $1 \mu \mathrm{g} / \mathrm{m}^{3}$ ) during graphitation (group G2 in our study). Similar observations were made in Sweden by Lindstedt and Sollenberg $^{15}$; benzo $(\alpha)$ pyrene concentration was below $0.1 \mu \mathrm{g} / \mathrm{m}^{3}$ in the graphitation area, below $1.3 \mu \mathrm{g} / \mathrm{m}^{3}$ near the baking oven (group G3 in our study), and below $40 \mu \mathrm{g} / \mathrm{m}^{3}$ in the impregnation area (group G6 in the present study). Pyrene has been detected in the air of all workplaces studied. Its relative abundance ranged from 2 to $8.5 \%$ of total PAHs. In spite of this low proportion, the concentration of pyrene was highly correlated with the total amount of PAHs in air $(\mathrm{r}=0.83, \mathrm{p}<0.0001)$. Jongeneelen et al $^{13}$ for coke ovens and Tolos et $a l^{16}$ for an aluminium plant reported similar high correlations $(r=0.88$ and 0.82 , respectively) confirming the validity of the choice of pyrene as a representative component of mixtures of PAHs. We found, moreover, that the sum of the concentrations of the carcinogenic PAH ben$\mathrm{zo}(x)$ pyrene, benz $(x)$ anthracene, and $\operatorname{dibenz}(\mathrm{a}, \mathrm{h})$ anthracene was highly correlated with the total concentration of PAHs in air $(r=0.9, p<0.0001)$ and with that of pyrene alone $(r=0.82, \mathrm{p}<0.0001)$.

As already mentioned, the amount of PAHs collected by personal samplers worn by different workers at the same workplace differed greatly, sometimes by several orders of magnitude, making a correct evaluation of the risk of overexposure difficult on the basis of air measurements. As suggested by Jongeneelen et $a l^{13}$ the urinary metabolite of pyrene was measured and its concentration in spot samples of postshift urine was shown to be highly correlated with the atmospheric concentration of pyrene $(r=0.66, p<$ $0.0001)$ and with that of total PAHs $(r=0.72, p<$ 0.0001 ); the second correlation was slightly higher probably because the overall workplace contamination was more adequately evaluated by the measurement of 13 PAHs than by that of pyrene alone. Our results agree with those recently reported by Tolos $e^{2} \mathrm{al}^{16}$; among 18 workers exposed to PAHs derived from coal tar pitch, they found a Spearman correlation coefficient of 0.61 between the change in concentration of urinary hydroxypyrene and environmental pyrene. The fact that Jongeneelen $e t$ $a l^{13}$ did not find a good correlation between the end of shift concentration of hydroxypyrene in urine and pyrene in air among coke oven workers was probably due to the small number of subjects.

Among subjects sustaining a low exposure to $\mathrm{PAH}$, smoking habits may cause a distinct increase in the excretion of hydroxypyrene in urine ${ }^{13}$ but the difference in excretion between smokers and non-smokers disappears as the intensity of exposure to PAH increases. In the present study, the relative contribution of smoking to the variance of the hydroxypyrene 
excretion in urine was negligible by comparison with that of the exposure to PAHs. A similar lack of significant effect of smoking on the excretion of hydroxypyrene was also found by Tolos et $a l^{16}$ in workers from a plant producing aluminium.

\section{Conclusions}

The present study confirms that the determination of hydroxypyrene concentrations in urine can be used as a suitable biomarker to assess individual exposure to PAHs in two different occupational settings. As the PAH exposure displays a high variability among workers at the same workplaces, the evaluation of health risk must ideally combine an environmental monitoring to detect emission sources and a biological monitoring (urinary excretion of hydroxypyrene) to take into account individual factors such as personal working habits, absorption routes (inhalation, skin contact, oral intake in smokers) and the use of personal protective equipment.

The half life for the urinary excretion of hydroxypyrene amounts to 18 hours indicating a possible accumulation of pyrene in the body during a work week. Therefore its measurement should preferably be performed in a urine sample collected at the end of the week.

\section{Appendix}

Conversion of units; hydroxypyrene, $1 \mu \mathrm{g}=4.58$ nmol; creatinine, $1 \mathrm{~g}=8.84 \mathrm{mmol} ; 1 \mu \mathrm{g}$ hydroxypyrene $/ \mathrm{g}$ creatinine $=0.518 \mu \mathrm{mol}$ hydroxypyrene/ mol creatinine.

This study was financially supported by the European Community of Coal and Steel and the Belgian State (Prime Minister's Service-Science Policy Office).

Requests for reprints to: Professor R Lauwerys, Industrial Toxicology and Occupational Medicine Unit, Catholic University of Louvain, 30.54, Clos Chapelle-aux-Champs, 1200 Brussels, Belgium.
1 International Agency for Research on Cancer. Monographs on the evaluation of the carcinogenic risk of chemicals to humans. Vol 32. Polynuclear aromatic compounds, part 1, Chemical, environmental and experimental data. Lyon: IARC, 1983.

2 Jongeneelen FJ, Bos RP, Anzion RB, Theuws JLG, Henderson PT. Biological monitoring of polycyclic aromatic hydrocarbon metabolites in urine. Scand J Work Environ Health 1986; 12:137-43.

3 International Agency for Research on Cancer. Monographs on the evaluation of the carcinogenic risk of chemicals to humans. Vol 34. Polynuclear aromatic compounds, part 3, industrial exposures in aluminium production, coal gasification, coke production and iron and steel founding. Lyon: IARC, 1984.

4 Lesage J, Perrault G, Durand P. Evaluation of worker exosure to polycyclic aromatic hydrocarbons. Am Ind Hyg Assoc J 1987;48:753-9.

5 Lankmajr EP, Müller K. Polycyclic aromatic hydrocarbons in the environment, high-performance liquid chromatography using chemically modified columns. J Chromatogr 1979; 170:139-46.

6 Das BS. Applications of HPLC to the analysis of polycyclic aromatic hydrocarbons in environmental samples. In: Lawrence JF. Liquid chromatography in environmental analysis. Totowa, NJ: Humana Press, 1984.

7 Jongeneelen FJ, Anzion RBM, Henderson PTh. Determination of hydroxylated metabolites of polycyclic aromatic hydrocarbons in urine. J Chromatogr 1987;413:227-32.

8 Pettigrew AR, Fell GS. Simplified colorimetric determination of thiocyanate in biological fluids, and its application to investigation of the toxic amblyopias. Clin Chem 1972;18:996-1000.

9 SAS/STAT Guide for personal computers version 6. Cary, North Carolina: SAS Institute Inc, 1987.

10 Horning RW, Reed L. Estimation of average concentration in the presence of nondetectable values. Applied Occupational and Environmental Hygiene 1990;5:46-51.

11 Ngogang J, Eben-Moussi E, Raisonnier A. Le thiocyanate salivaire, urinaire et plasmatique des fumeurs et des nonfumeurs. Pathol Biol 1983;31:155-60.

12 Masek V. Hydrogen cyanide in the air of coking plant working environment. Zentralblatt Arbeitsmedizin Arbeitsschutz 1974; 24:101-5. (In German).

13 Jongeneelen FJ, Van Leeuwen FE, Oosterink S, et al. Ambient and biological monitoring of coke oven workers: determinants of the internal dose of polycyclic aromatic hydrocarbons. $B r J$ Ind Med 1990;47:454-61.

14 Lafontaine M, Attenont H, Truy S. Exosition aux hydrocarbures polycycliques aromatiques dans l'industrie productrice d'électrodes en carbone. Cahiers de Notes Documentaires 1988;132:453-7.

15 Lindstedt G, Sollenberg J. Polycyclic aromatic hydrocarbons in the occupational environment. Scand J Work Environ Health 1982;8:1-19.

16 Tolos WP, Shaw PB, Lowry LK, Mackenzie BA, Deng JF, Markel HL. 1 Pyrenol: a biomarker for occupational exposure to polycyclic aromatic hydrocarbons. Applied Occupational and Environmental Hygiene 1990;5:303-9.

Accepted 27 January 1992 